\title{
A Speed Based Congestion Study of a Road Section Connecting Fulbarigate-Dakbangla, Khulna
}

\author{
Palash Chandra Das*, Neeti Zaman Bintee and A.K. Azad \\ Department of Urban and Regional Planning, Khulna University of Engineering \& Technology (KUET), Khulna -9203, Bangladesh
}

Received 06 Sept 2018, Accepted 10 Nov2018, Available online 12 Nov, Vol.8, No.6 (Nov/Dec 2018)

\begin{abstract}
Congestion, a problem that is not new for a third world country like Bangladesh. Like the other megacities of Bangladesh, Khulna is gradually experiencing this phenomenon in an acute manner. Khulna-Jessore highway that runs through the city and gives it a linear form works as the backbone of the traffic skeleton of Khulna city. This study focuses on developing a speed based model for predicting congestion scenario of Khulna city. Fulbarigate to Dakbangla midblock is chosen as the study corridor. The whole study corridor $(10.73 \mathrm{~km})$ is divided into two equal halves and travelled 10 times with the stream and against the stream to generate 20 data set. Speedometer GPS survey along with moving observed method is used to collect necessary data. A latitude longitude based speed profile is found at each travel based on which travel speed index (TSI) is calculated and a multiple linear regression (MLR) model for predicting congestion is developed. Independent variables are selected based on the possibility of affecting congestion of the road section. The MLR model is found as TSI $=0.0167083+0.0001826^{*}$ Volume $(P C U / h r)+$ $0.0019625^{*}$ Speed Drop Factor, with 8.86 \% error. Congestion is found severe at Doulatpur Bazar and Shibbari to Dakbangla circle within the study corridor. Due to illegal parking spot, road capacity is not utilizing properly. As a result in peak hour, speed drops more than average peak hour speed and congestion occurs.
\end{abstract}

Keywords: Traffic Congestion, Moving Observer Method, MLR Model, Speedometer GPS, Speed profile

\section{Introduction}

Congestion, a term that is making urban life slower, generates such a trouble that is now seeking attention in almost all developing as well as developed countries. Since the end of the Second World War, high demand for mobility increases due to rapid urbanization and economic growth in third world cities (Chakrabartty, et al, 2015). In a third world country like Bangladesh, traffic congestion is faced by almost all the mega cities like Dhaka, Chittagong etc. (Shamsher, et al, 2013). The congestion scenario of mega cities is enough to predict the alarming situation for the cities under major infrastructural development. Khulna, the third largest city of Bangladesh, in such case is the next to recur the same incidence (Moniruzzaman, 2013). Major development projects e.g. Padma Bridge, KhulnaMongla Rail Road project have been taken to link Khulna with the other parts of the country in order to accelerate the economic growth of Bangladesh (Bangladesh Bridge Authority, 2017). Again, traffic information is now required by vehicle drivers, traffic police, and road construction planners. Drivers want to know the status of the road to avoid traffic congestion. The traffic police demand information on intersections

*Corresponding author's ORCID ID: 0000-0003-4523-2430 DOI: https://doi.org/10.14741/ijcet/v.8.6.8 to reduce traffic jam through improvement of signal system. Transport planners use traffic information as one of the factors for choosing locations where road expansion is required. Thus predicting the present scenario of congestion in Khulna city is necessary to identify the congested nodes throughout the city.

The objective of the study is to develop a prediction model of traffic congestion for heterogeneous traffic. To fulfill the objective, two research questions are formulated. First one is to identify the present scenario of traffic congestion in Khulna City and second one is to identify the factors affecting traffic congestion. This study generates a prediction model regarding the traffic congestion scenario of Khulna city. Main reasons behind the congestion can be sorted out through this speed based congestion study. Finally, this study would enable policy makers to take decisions regarding Khulna city transportation by ensuring efficient resource allocation before the congestion scenario gets even worse.

\section{Literature Review}

\subsection{Traffic Congestion}

Congestion can be of two main types- Recurrent (too many vehicles using the same road at the same time), Non-recurrent (disabled vehicles, accidents, work 
zones such as street cleaning) congestion (Chakrabartty, et al, 2015). Remiet al. (2009) defined traffic congestion as a condition that occurs while road use increases characterized by slower speeds, longer trip times, increased number of vehicles. Congestion is a condition, arises as more people wish to travel at a given time than the transportation system can accommodate, can be represented as a simple case of demand exceeding supply (Miller, et al., 1994). It also takes place when travel demand exceeds the existing road system capacity (Rosenbloom, 1978).

\subsection{Generation of Traffic Congestion}

Traffic congestion occurs on fixed road capacity exceeding $90 \%$ of the capacity. As a result, level of service (LOS), which is measured by speed or delay, deteriorates to unacceptable level. The growth of traffic is affected by four major factors : (1) the natural growth of population, (2) locational patterns (i.e. spatial distribution of residence, work, shopping and places of recreation), (3) transportation characteristics and policies, and (4) transport behavior of individuals and household manifested in their mode choice, departure time, route choice and so on (Papacostas, et al., 2001).

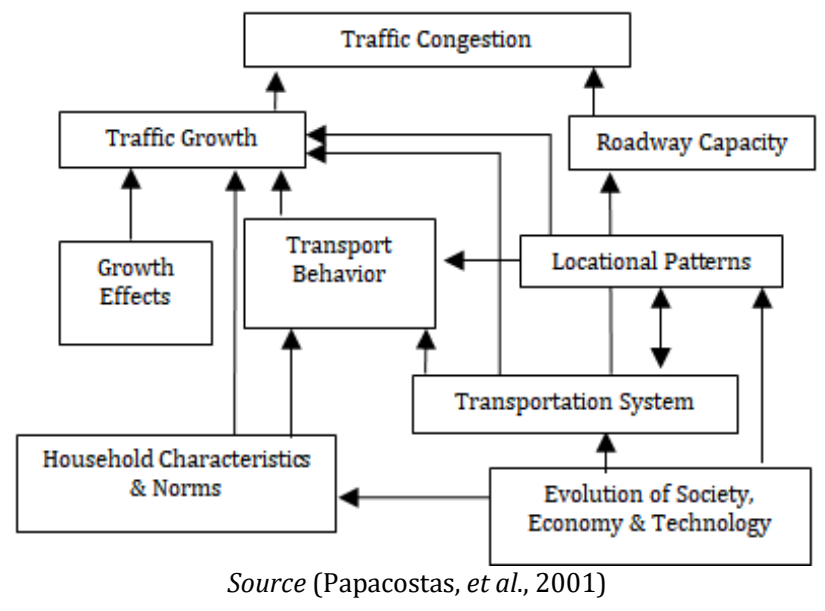

Fig.1 Causes of generating congestion

\subsection{Congestion Measuring Parameters}

Levinson and Lomax (1996) developed a congestion index which measures the differences in actual versus desired travel time. Congestion index (CI) can be represented as the ratio of mean travel time to freeflow travel time (McDonald, et al.). Lomax et al., (1997) defined corridor mobility index (CMI) as a measure of person-carrying capacity of corridors. Travel rate index (TRI) measures amount of additional time required to make a trip because of congestion (Das, et al, 2016).

Buffer time index measures extra percentage of travel time that a traveler should allow when making a trip in order to be on time $95 \%$ of the time. Traveler adds this amount of time onto a trip when planning trips (Kansas and Missouri Departments of Transportation, 2011).
Lindley denoted a situation as congestion while volume to capacity ratio exceeds 0.77 (Lindley, 1987). Roadway congestion index (RCI), developed by Shrank and Lomax (2005), is a measure of daily VMT (Vehicle Miles Travelled) per lane-mile of freeways and principal arterial streets. It is an empirically derived formula to quantify the relative congestion levels across metropolitan areas (Rao and Rao, 2012). Lanemile duration index (LMDI), by Cottrell (1991), calculates average annual daily traffic volume per hourly capacity (Rao and Rao, 2012).

\subsection{Congestion Measuring through TCS}

In the year of 2016 Das, et al, established an MLR model based on traffic congestion score (TCS) derived from speed against distance curve. A two km study corridor was selected. An average speed of peak time was considered as the standard speed in peak hour. Vbox was used to collect speed data profile based on distance (m). In the speed vs. distance curve the area between the standard speed and the speed observed below this is termed as congestion patch area. Volume/km, vehicle composition, friction spot and speed drop factor were considered as independent variables for this model (Das, et al, 2016).

\subsection{Congestion Measuring through TTI}

In 2016, Henry and Koshy developed an MLR model to predict traffic congestion using travel time index (TTI) as dependent variable. Number of pedestrians crossing the traffic stream, Volume of crossing, merging and diverging traffic, sum of average dwell time of buses was considered as independent variables here. For this study, a $1.4 \mathrm{~km}$ state highway- 1 section (between Kumaranalloor and Gandhi Nagar, Kottayam of Kerala state, India) was taken. Moving car method was conducted to derive actual travel time of car both in morning and evening peak periods. This study area had heterogeneous traffic though number of car was the most comparing to other vehicles. From the analysis of hourly variation of congestion it was found that vehicles take $81 \%$ to $133 \%$ longer travel time in traversing the section (Henry and Koshy, 2016).

\subsection{Congestion Prediction Model using R Programming}

$\mathrm{R}$ is a language and environment for statistical computing and graphics that provides a wide variety of statistical linear and nonlinear modeling. Lee, et al, performed an MLR analysis for predicting the changes in traffic congestion based on weather data in 2015. The data used in the analysis included weather data in the residential area, the destination as well as traffic congestion data in the destination. Altogether 48 independent variables were used in the regression analysis, including temperature, humidity, and cloud, rainfall, and wind velocity. Six days of week were considered as six dummy variables to fit the MLR model. Regression models were not created for each 
day of the week. Instead, a single model for the entire week was created. To process weather and traffic data sets Hadoop software was used. Dependent variable traffic congestion score (TCS) was calculated using Hadoop software considering speed profile of link roads. Time required to travel $1 \mathrm{~km}$ road section was calculated by the aggregation method here. Then $\mathrm{R}$ programming was used to remove variable and justify multiple linear regression model. The final prediction model presents accuracy level more than $75.5 \%$ with the actual result.

\subsection{MLR Modeling through GPS Data}

Satyakumar, et al, in 2012 formulated an MLR model using GPS data. Both peak and off-peak hour congestion were considered in this model. Separate models were developed for 2 wheelers, 3 wheelers, cars and public transit vehicles for morning and evening peak hours. Kesavadasapuram-Pattom stretch in India was considered as study area. GIS software was used as a database for storing and manipulating transportation data collected through GPS. Variation of congestion indices (LOS, $\mathrm{CI}$, travel rate ratio, $\mathrm{v} / \mathrm{c}$ ratio, and delay rate index) were represented using GIS software. Here, speed was considered as dependent variable. Finally, regression model through SPSS software derived the equation with an R-squared value of 0.852: Speed (public transits) $=28.74-0.004 \mathrm{TW}$ $0.059 \mathrm{~A}+0.004 \mathrm{C}-0.096 \mathrm{~B}-0.644 \mathrm{G}+$ 0.014 PTW - 0.238 PA - 0.014 PC - 0.258 PG; Where, $\mathrm{A}=$ Number of auto, $\mathrm{PA}=$ Number of autos parked, $\mathrm{B}=$ Number of bus, $\mathrm{PG}=$ Number of goods vehicle parked, $\mathrm{C}=$ Number of cars, $\mathrm{PC}=$ Number of parked cars, $\mathrm{TW}=$ Number of two wheelers, $\mathrm{G}=$ Number of goods vehicle, PTW $=$ Number of parked two wheelers.

\section{Study Area}

Khulna is the $3^{\text {rd }}$ largest city after Dhaka and Chittagong having a population of 759877 (Ministry of Planning, 2015). Khulna is located in South-West part of Bangladesh at $22^{\circ} 49^{\prime} 0^{\prime \prime} \mathrm{N} 89^{\circ} 33^{\prime} 0^{\prime \prime} \mathrm{E}$, on the banks of the Rupsha and Bhairab River. The city has a strong industrial base on shrimp cultivation, which is the second biggest foreign exchange earner in Bangladesh (Ahmed, 2011). Major industries (Jute mills, Saw Mills etc.), trade and commerce are developed beside Khulna-Jessore highway. For this study, a road section from Fulbarigate to Dakbangla circle was considered as this is the highly congested road section in Khulna City Corporation area. Total length of the study road section was $10.73 \mathrm{~km}$. As a whole 10 types of modes are available throughout the road sections. Here public transport vehicles are higher in number than private vehicles (i.e. car).
Table 1 Modes available in the study route

\begin{tabular}{|c|c|}
\hline Mode of Transport & Mode of Transport \\
\hline Bus & Rickshaw \\
\hline Truck & Van \\
\hline Auto & Motor cycle \\
\hline CNG & Cycle \\
\hline Mahindra & Car \\
\hline \multicolumn{2}{|c|}{ Source Field Survey, 2018 } \\
\end{tabular}

Seven road sections have been considered to conduct volume survey. Major intersections are considered to divide the whole study corridor into seven sections. Sections which have been considered are mentioned below in Table 2 .

Major intersections throughout the study area are named by Fulbarigate, Doulatpur, Notun Rasta Circle, Shibbari Circle, Powerhouse Circle, Ferryghat and Dakbangla Circle. Physical feature survey has also been conducted throughout the study road sections.

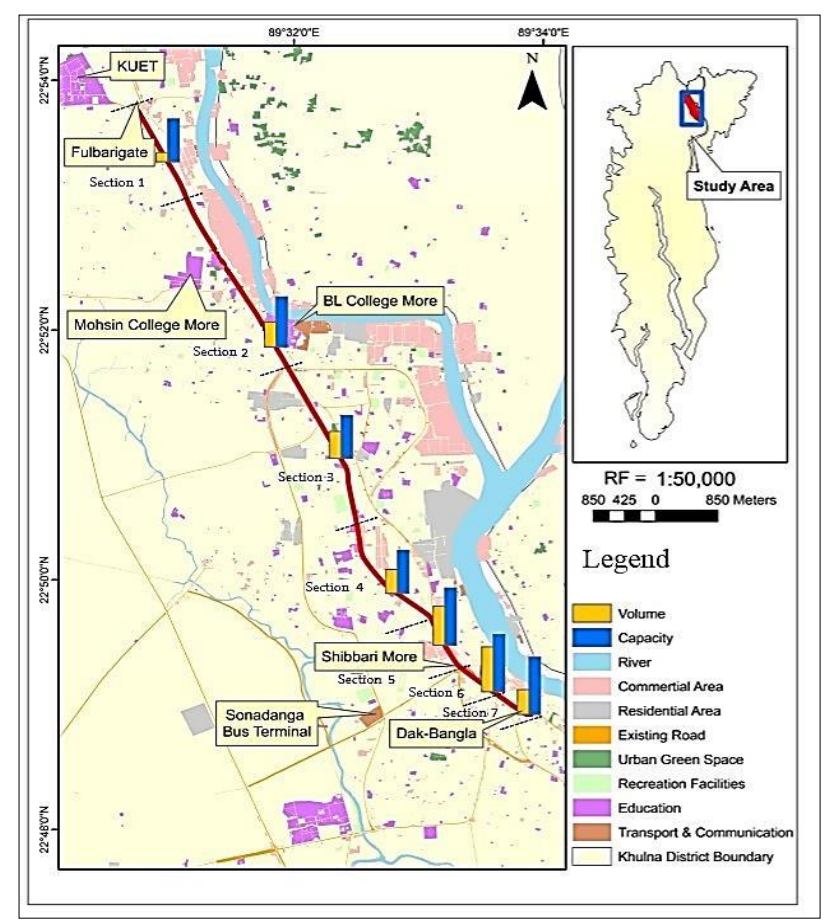

Fig. 2 Map of the Study Corridor;SourceAuthor, 2018

Table 2 Physical features throughout the road section $\mathrm{s}$

\begin{tabular}{|c|c|c|c|c|c|}
\hline 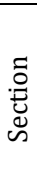 & 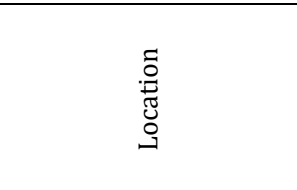 & 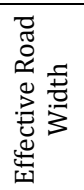 & 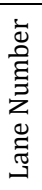 & 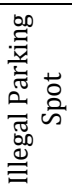 & 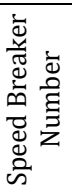 \\
\hline 1 & $\begin{array}{c}\text { Fulbarigate to Notun } \\
\text { Rasta } \\
\end{array}$ & $35^{\prime}$ & 1 & 2 & 2 \\
\hline 2 & Notun Rasta to Boyra & $44^{\prime}$ & 2 & 4 & 3 \\
\hline 3 & Boyra to Joragate & $40^{\prime}$ & 1 & 2 & 1 \\
\hline 4 & Joragate to Shibbari & $35^{\prime}$ & 1 & 4 & 4 \\
\hline 5 & Shibbari to Powerhouse & $35^{\prime}$ & 1 & 1 & 2 \\
\hline 6 & $\begin{array}{c}\text { Powerhouse to } \\
\text { Ferryghat }\end{array}$ & $35^{\prime}$ & 1 & 0 & 3 \\
\hline 7 & Ferryghat to Dakbangla & $44^{\prime}$ & 2 & 7 & 0 \\
\hline
\end{tabular}


Overall volume to capacity ratio shows how smoothly the vehicles can operate on the facility. This ratio remains highest $(0.784)$ in case of Powerhouse to Ferryghat Circle which is considered to be the most congested section within the study corridor (Table 3).

Table 3 Section specific $V / C$ ratio

\begin{tabular}{|c|c|c|c|}
\hline Section & Volume (PCU/hr) & Capacity (PCU/hr) & V/C ratio \\
\hline 1 & 910.6 & 4200 & 0.21681 \\
\hline 2 & 1979 & 5600 & 0.353393 \\
\hline 3 & 2643.3 & 4200 & 0.629357 \\
\hline 4 & 2343.6 & 4200 & 0.55800 \\
\hline 5 & 3819.3 & 5600 & 0.682018 \\
\hline 6 & 4391.7 & 5600 & 0.784232 \\
\hline 7 & 2424.9 & 5600 & 0.433018 \\
\hline \multicolumn{3}{|c|}{ Source Field Survey, 2018 } \\
\hline
\end{tabular}

\section{Methodology}

To identify congested nodes throughout the study route, Speedometer GPS app along with moving observer method has been used. Here Speedometer GPS app is used to identify location specific congestion. Congestion patch area has been identified where speed falls below the average speed of each peak hour travel. The record of this app has been extracted through Google Earth. At every two minutes interval a ground control point (GCP) has been located in Google Earth through the app. Then distance between two consecutive points has been measured. Thus latitude longitude based journey speed (in $\mathrm{KPH}$ ) has been extracted. Value of the dependent variable travel speed index (TSI) has been calculated using the formula (Das, et al, 2016).

$$
T S I=\frac{\text { Congestion patch area }}{\text { Maximum congestion patch area }}
$$

Congested patch area is the area (P1, P2, P3) marked by the average speed line of the study corridor covering the speed profile observed below the average speed line and maximum congestion patch area (A1, A2, A3) is marked below the speed profile line for the congestion stretch up to zero reference speed i.e. when the vehicle is in stopped condition the congestion is maximum (Fig. 4). Moving observer method has also been used to identify the value of 8 independent variables (Table 4). The study corridor is divided into two equal halves (5.36 $\mathrm{km}$ each) and this survey procedure has been repeated 10 times in peak hour with the stream and against the stream to generate 20 data sets for the MLR model. A test car has been used to collect necessary data with the app. TSI is calculated each time and the changes in the value of independent variables are recorded.

Table 4 List of independent variables for MLR model

\begin{tabular}{|c|c|}
\hline Volume (PCU/hr.) & Speed drop factor \\
\hline $\begin{array}{c}\text { \% of } 2 \text { wheelers } \\
\text { (i.e. cycle, bike) }\end{array}$ & $\begin{array}{c}\text { of } 4 \text { wheelers } \\
\text { (i.e. Bus, car) }\end{array}$ \\
\hline $\begin{array}{c}\text { \% of } 3 \text { wheelers } \\
\text { (i.e. Mahindra, auto) }\end{array}$ & $\begin{array}{c}\text { \% of commercial vehicles (i.e. } \\
\text { truck, van) }\end{array}$ \\
\hline Friction Spot & Dwell time of test vehicle \\
\hline
\end{tabular}

Statistical programming language $\mathrm{R}$ has been used to generate a multiple linear regression (MLR) model including 8 independent variables which possibly affect the dependent variable TSI (Proxy variable for congestion). The variables that are not significant have been removed by backward test, multicollinearity test and significance test as mentioned in Fig 5.

\subsection{Congested Node Identification}

From the speed profile, congested areas of the study corridor have been identified for each peak hour travel. A sample of such speed profile is mentioned below (Fig. 4). From the speed profile curve, friction spots are counted for each travel i.e. the number of times speed falls below the average peak hour speed (red line).

Speed drop factor is considered as the deviation of average speed and actual speed in the congestion stretch along the profile.

The value of TSI has been used to identify the congested nodes i.e. the higher the value of TSI, the higher the level of congestion. The congestion patch areas needed to calculate TSI have been estimated using MATLAB.

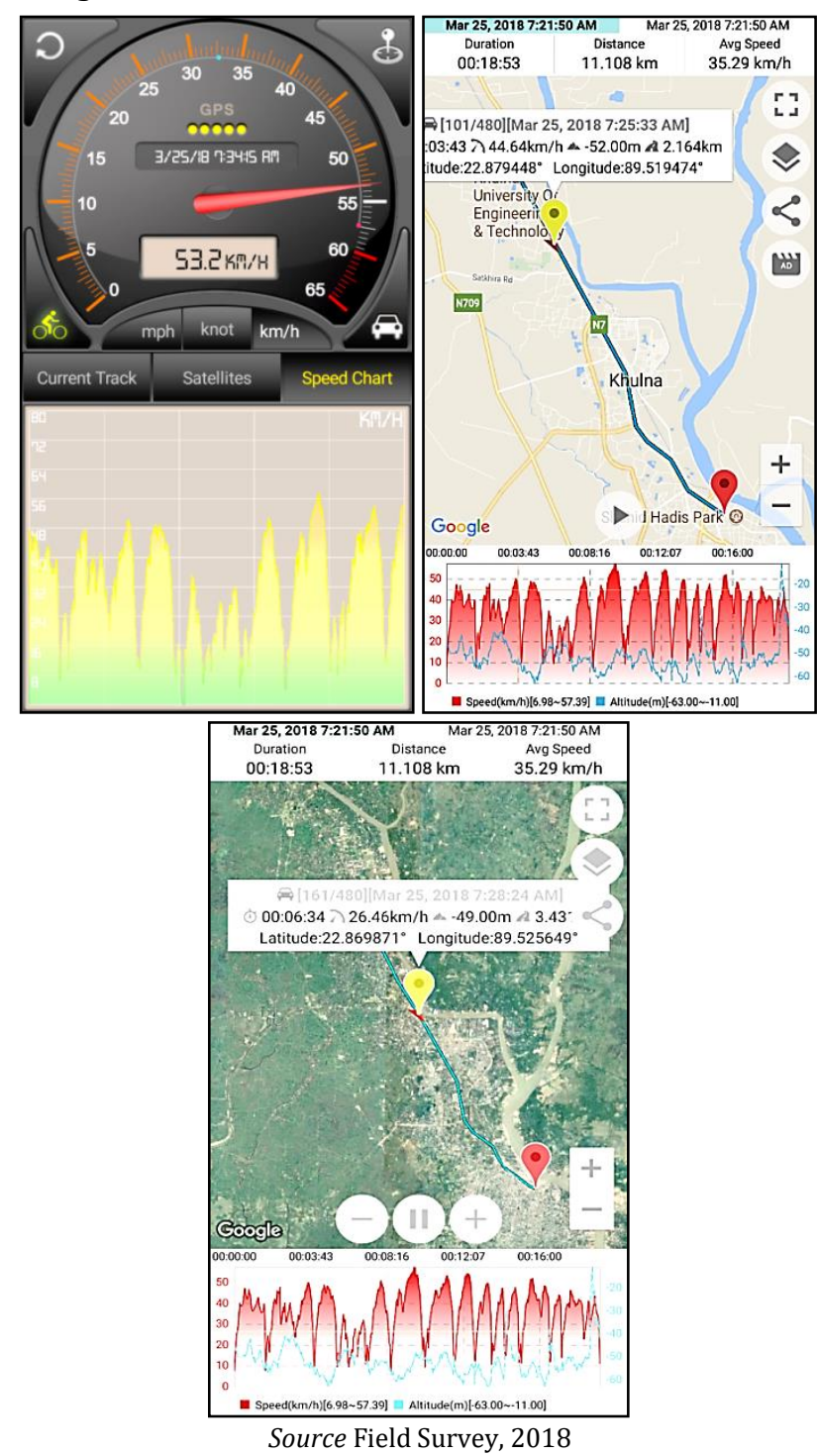

Fig. 3The Interface of Speedometer GPS App 


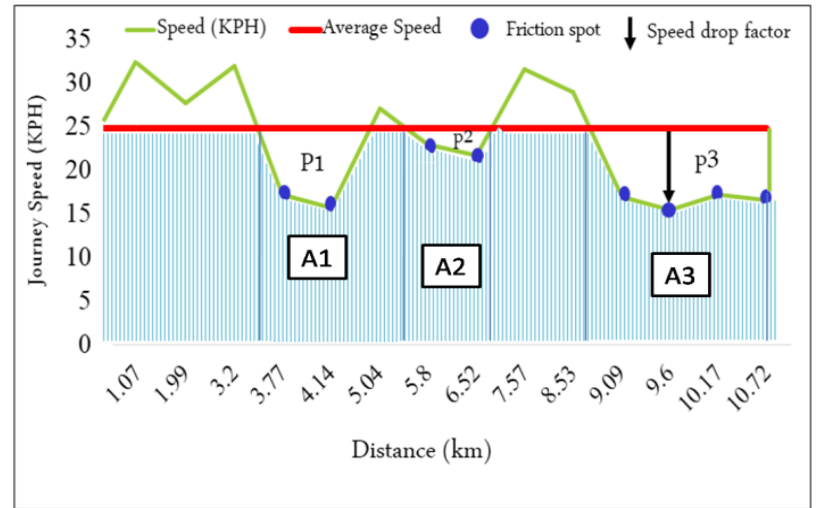

Source Author's Calculation, 2018

Fig. 4A Sample Speed Profile for the Study Corridor

\subsection{Identification of Possible Factors Contributing to Congestion}

From volume to capacity ratio it is found that in some places congestion has not been found at all. But through speed profile, those locations are found congested at several times. For example, in Doulatpur, $\mathrm{V} / \mathrm{C}$ ratio is estimated 0.35 . There should not be any congestion as the $\mathrm{V} / \mathrm{C}$ ratio is less than 0.7 (Lindley, 1987). But congestion does exist there as road capacity is not utilized properly due to illegal on-street parking and road side informal businesses. If road capacity can be utilized fully, congestion will not exist in such places even in peak hours.

\subsection{Notations used in MLR Model}

Dependent variable: TSI $=$ Travel Speed Index

Probable independent variables:

1) Volume $(\mathrm{PCU} / \mathrm{hr})=$ Volume of the stream per half $(5.365 \mathrm{~km})$ of the total road section

2) $\% 2 \mathrm{~W}=$ Percentage of two wheeler vehicles (i.e. motor cycle, cycle) among the total volume (PCU/hr.) of a section

3) $\% 3 \mathrm{~W}=$ Percentage of three wheeler vehicles (i.e. rickshaw, Mahindra, auto, CNG) among the total volume (PCU/hr.) of a section

4) $\% 4 \mathrm{~W}=$ Percentage of four wheeler vehicles (i.e. bus, car) among the total volume (PCU/hr.) of a section

5) $\% \mathrm{CV}=$ Percentage of commercial vehicles (i.e. truck, van) among the total volume (PCU/hr.) of a section

6) Dwell Time = Stoppage minutes required for boarding and alighting time of the passengers (minutes)

7) Friction Spot $=$ Number of times speed drops from the average speed

8) Speed Drop Factor $=$ Difference between average speed and actual speed (KPH)
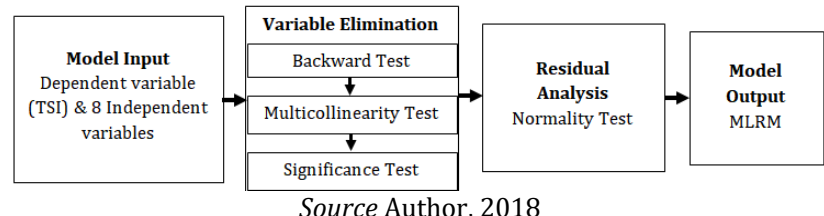

Fig. 5 MLR model development through RStudio

\subsection{Developing MLR Model in RStudio}

\section{Linear Regression Model Formulation}

A linear regression model has been formulated considering 20 data set of TSI against 8 independent variables. Although R squared value is found suitable (0.62), $p$-value for each independent variable is greater than 0.05 (at 95\% confidence level). So, the second step (Backward test i. e. Correlation test) has been followed to identify independent variables which have significant relationship with the dependent variable (TSI).

\section{Correlation Test}

The correlation test has been conducted afterwards. Considering the degrees of freedom, residuals and deviances six independent variables have been removed which are not correlated with congestion (TSI variable). Finally, an ANOVA test has been performed to justify the removal of six independent variables.

\section{Multicollinearity Test}

Two independent variables i.e. volume and speed drop factor are remained after the correlation test. Then multicollinearity between these variables has been tested to see the correlation among the independent variables. It is found that TSI has a good relationship with volume and speed drop factor whereas the correlation between volume and speed drop factor is not that significant (Table 5).

Table 5 Multicollinearity test of selected variables

\begin{tabular}{|c|c|c|c|}
\hline & TSI & $\begin{array}{c}\text { Volume } \\
\text { (PCU/hr.) }\end{array}$ & $\begin{array}{c}\text { Speed Drop } \\
\text { Factor }\end{array}$ \\
\hline TSI & 1 & 0.6473814 & 0.5706702 \\
\hline $\begin{array}{c}\text { Volume } \\
\text { (PCU/hr.) }\end{array}$ & 0.6473814 & 1 & 0.3886283 \\
\hline $\begin{array}{c}\text { Speed Drop } \\
\text { Factor }\end{array}$ & 0.5706702 & 0.3886283 & 1 \\
\hline \multicolumn{4}{|c|}{ Source Author's Calculation, 2018 } \\
\hline
\end{tabular}

Normality Test

To determine whether the data set used in this model is normally distributed or not, Shapiro-Wilk normality test has been conducted (Table 6). Here, p-value is found 0.3201 which is greater than 0.05 , suggesting normal distribution (Lee, et al, 2015). 
Table 6 Shapiro-Wilk Test

$\mathrm{W}=0.94673 \quad$ p-value $=0.3201>0.05$

Source Author's Calculation, 2018

\subsection{Regression Statistics}

\section{Coefficient of Determination}

The adjusted R-squared value is 0.4848 which signifies that the variation in TSI is $48.48 \%$ explained by volume and speed drop factor. Again, the p-value is less than 0.05 . So, the model is a good fit (Table 7).

Table 7 Regression results for congestion analysis

\begin{tabular}{|c|c|c|c|c|}
\hline & Estimate & Std. Error & t value & p-value \\
\hline (Intercept) & 0.0167083 & 0.0217740 & 2.740 & 0.0434 \\
\hline $\begin{array}{c}\text { Volume } \\
\text { (PCU/hr.) }\end{array}$ & 0.0001826 & 0.0000651 & 2.805 & 0.0122 \\
\hline $\begin{array}{c}\text { Speed Drop } \\
\text { Factor }\end{array}$ & 0.0019625 & 0.0009332 & 2.103 & 0.0507 \\
\hline \multicolumn{4}{|c|}{ Multiple R-squared: 0.539, Adjusted R-squared:0.4848, p- } \\
value:0.001384
\end{tabular}

Source Author's Calculation, 2018

Variables in the Equation

The equation found is: $\mathrm{TSI}=0.0167083+0.0001826^{*}$ volume (PCU/hr.) + 0.0019625* speed drop factor. The p-value for intercept, volume and speed drop factor is found less than 0.05 at a confidence interval of $95 \%$. So; the intercept, volume and speed drop factor significantly explain the dependent variable TSI i.e. congestion.

F-test

From the F-distribution table it is found that at a significance level of 0.05 and with a degree of freedom of (df) $17, F$ critical value is 2.168 and the value of $F$ computed is 9.939. As F computed > F critical, the null hypothesis $\mathrm{H}_{0}$ is rejected at a significance level of 0.05 . It defines that the TSI is dependent on independent variables i.e. volume and speed drop factor.

t-Test

From the t-distribution table it is observed that at a significance level of $0.05, t$ critical value is 1.740 , and the value of | $t$ computed | for dependent and independent variables are 2.74, 2.805 and 2.103 respectively. As | t computed | $>\mathrm{t}$ critical, the null hypothesis $\mathrm{H}_{0}$ for each of the three variables is rejected at a significance level 0.05 .

Considering the sign of the estimated coefficients, it can be concluded by saying that both of the independent variables have proper sign. The equation may therefore be used for further congestion studies of the study area.

\section{Model Validation}

In this section, MAPE (Mean Absolute Percentage Error) has been used to evaluate the proposed MLR model. It is defined by the following equation where $A_{t}$ is the actual value and $F_{t}$ is the forecasted value (Lee, et 1,2015 ).

$M=\frac{1}{n} \sum_{t=1}^{n}\left|\frac{A_{t}-F_{t}}{A_{t}}\right|$

It is estimated that the model accounts for $8.86 \%$ error.

\section{Summary of the MLR Model}

The final regression model shows a positive correlation between volume (PCU/hr) of the study area and congestion index TSI. In real, congestion of the road section increases while total volume increases. This volume data consists of 3 wheeler, 4 wheeler and 2 wheeler vehicles. So vehicle composition variables have got removed in multicollinearity test. Again, a positive correlation exists between TSI and speed drop factor. It mainly happens due to larger boarding and alighting time of passengers. Doulatpur Bazar, Shibbari Circle, Power House and Ferryghat Circle are found to be the most congested nodes within the study corridor.

\section{Overall Findings}

1) In case of Khulna, two major peak hours existone in the morning and another is evening peak. Congestion is acute and more time consuming in evening peak.

2) In Shibbari, Ferryghat, Power house \&Dakbangla Circle, speed drop phenomenon is less than Doulatpur Bazar.

3) In Daulatpur, although the $V / C$ ratio is 0.35 . There should not be any congestion as $\mathrm{V} / \mathrm{C}$ ratio is less than 0.7 (Lindley, 1987). Illegal on-street parking and road side informal businesses are the reasons contributing to this (not utilizing the capacity of road).

\section{Conclusion}

The present study portrays the importance of using Travel Speed Index (TSI) in defining traffic congestion of urban heterogeneous traffic. For this work a review of past studies on different congestion measures have been done and their merits and demerits are compared from which Travel Speed Index (TSI) is found to be a convenient congestion measure. From the traffic composition in the selected stretch, it is evident that majority of the vehicles are three wheelers. From the MLR model it is observed that congestion (TSI) can be explained with the term of volume and speed drop factor. 


\section{Limitations}

Geometric factors like the radius of curvature of the road and influence of the width of road and surface aren't considered in the MLR model.

\section{References}

The Schemmer Associates. 2006.Vehicle Occupancy Study. Lincoln :s.n., 2006.

A Prediction Model of Traffic Congestion Using Weather Data.Lee, Jiwan ,et al. 2015. 2015, IEEE International Conference on Data Science and Data Intensive Systems, pp. 81-88.

Alvi, Mohsin. 2016.A Manual for Selecting Sampling Techniques in Research. Karachi : Munich Personal RePEc Archive, 2016.

Bangladesh Bridge Authority.2017. Present Status of the Project. Bangladesh Bridge Authority.[Online] February 2017. [Cited: July 7, 2017. www.padmabridge.govt.bd/ cstatus.php.

BBS. 2013.District Statistics 2011. Dhaka: Bangladesh Bureau of Statistics , 2013.

Black, Alan. 1995. Estimating System Costs. [ed.] James W. Bradley B. J. Clark. Urban Mass Transportation Planning. Brekeley : McGraw-Hill, 1995, pp. 329-347.

Committee of Transport Officials. 2013.South African Trip Data Manual. s.l.: The South African National Roads Agency Limited, 2013.

Congestion Modelling for Heterogeneous Traffic.Henry, Sruthy and Koshy, Bino I. 2016. 2016, International Journal of Engineering Research \& Technology, pp. 114-119.

Cost-Benefit analysis for freight transportation of Bangladesh.Nasirullah, Sayed, Mortuza, Md.Rubayet and Hossain, Moazzem. 2011.Dhaka :s.n., 2011.

Determination and Evaluation of Traffic Congestion Costs.Hansen, Ingo . 2000. 2000, Transportation Planning and Traffic Engineering Section, pp. 61-72.

Determination of congestion charge for car users in Cbd area of thiruvananthapuram city.Sunny, Tina Maria and Thomas, Jomy. 2015. 2015, International Journal of Research in Engineering and Technology, pp. 220-227.

Estimating Costs of Traffic Congestion in Dhaka City.Khan, Tanzila and Islam, Rashedul. 2013. 2013, International Journal of Engineering Science and Innovative Technology (IJESIT), p. 281.

Estimation of Congestion Cost in the City of Kolkata-A Case Study. Chakrabartty, Aparajita and Gupta, Sudakshina. 2015. 2015, Scientific Research Publishing, pp. 95-104.

Estimation of Traffic Congestion Cost-A Case Study of a Major Arterial in Karachi.Ali, Mir Shabbar, et al. 2013. 2013, Procedia Engineering, pp. 37-44.

Guttikunda, Dr. Sarath. 2008.Simple Interactive Models for Better Air Quality. India: Vehicular Air Pollution Information System, 2008.
Kadiyali, L.R. 1997.Traffic Engineering and Transport Planning. Delhi :Khanna Publishers, 1997.

Kansas and Missouri Departments of Transportation. 2011.Congestion Index Report. Kansas : Kansas City Scout, 2011.

LGED. 2009.Road user cost study for lged roads. Dhaka LGED, 2009.

McDonald, Mike ,et al.Urban traffic management: the viability of short term congestion forecasting using artificial neural networks. U.K. : Transportation Research Group, University of Southampton.

Measuring urban traffic congestion - a review.Rao, Amudapuram Mohan and Rao, KalagaRamachandra. 2012. 2012, International Journal for Traffic and Transport Engineering, pp. $286-305$.

Miller , M. A. and Li, K. 1994.An investigation of the costs of roadway traffic congestion: a preparatory step for IVHS benefits' evaluation. Berkley: Institute of Transport Studies, University of California, 1994.

Ministry of Planning. 2015.Bangladesh Population and Housing Census 2011. Dhaka: Bangladesh Bureau of Statistics, 2015

ModellingSpatio-Temporal Urban Land Cover Growth Dynamics Using Remote Sensing and GIS Techniques: A Case Study of Khulna City.Ahmed, Bayes. 2011. 2011, Bangladesh Institute of Planners, pp. 15-32.

Moniruzzaman, Md. 2013.Sustainable and inclusive transport development of Khulna City.Khulna: Khulna City Corporation, 2013.

Papacostas, C. S. and Prevedouros, P.D. 2001.Transportation Engineering \& Planning.New Jersey : Prentice Hall, 2001.

Peak-period traffic congestion: a state-of-art analysis and evaluation of effective solution. Rosenbloom, S. 1978. 2, 1978, Transportation, Vol. 7, pp. 167-191.

Satyakumar, M. and Anil, R. 2012.Estimating traffic congestion \& los on urban roads using Gps data.Trivandrum :s.n., 2012.

Singh, Gurcharan and Singh, Jagdish. 2006. Highway Engineering. 3rd. Delhi : Standard Publishers Distributors, 2006.

Traffic Congestion Modelling with Reference to Speed Profiles under Mixed Traffic Conditions: A Case Study of Surat Corridor. Das, AathiraK, Saw, Krishna and Katti, B K . 2016. 2016, Global Research and Development Journal for Engineering, pp. 381-386.

Traffic in Congestion in Bangladesh- Causes and Solutions: A Case Study of Chittagong Metropolitan City. Shamsher, R. and Abdullah, N. M. 2013. 2013, Asian Business Review, pp. 13-18.

Traffic Studies and Urban Congestion.Smeed, R. J. 1968. 1968, Journal of Transport Economics and Policy, Vol. 2, pp. 3370.

Urban freeway congestion: quantitcation of the problem and effectiveness of potential solutions. Lindley, J. A 1987.1987, Institute of Transportation Engineers Journal, pp. 27-32.

Value of Time for Commuting Motorists.Thomas, C. 1968 1968, Highway Research Record, Vol. 245, pp. 17-35. 